\title{
The North Atlantic Oscillation and European vegetation dynamics
}

\author{
Célia Gouveia, ${ }^{\mathrm{a}, \mathrm{b}}$ Ricardo M. Trigo, ${ }^{\mathrm{a}, \mathrm{c} *}$ Carlos C. DaCamara, ${ }^{\mathrm{a}}$ Renata Libonati ${ }^{\mathrm{a}}$ \\ and José M. C. Pereira ${ }^{\mathrm{d}}$ \\ a IDL-CGUL, Faculdade de Ciências, Universidade de Lisboa, Portugal \\ b Escola Superior de Tecnologia, Instituto Politécnico de Setúbal, Setúbal, Portugal \\ c Departamento de Engenharias, Universidade Lusófona, Lisboa, Portugal \\ d Department of Forestry, Instituto Superior de Agronomia, Technical University of Lisbon, Portugal
}

\begin{abstract}
The relationship between vegetation greenness and the North Atlantic Oscillation (NAO) is assessed over Europe. The study covers the 21-year period from 1982 to 2002 and is based on monthly composites of the Normalised Difference Vegetation Index (NDVI) and Brightness Temperature from the Global Inventory Monitoring and Modelling System (GIMMS) as well as on monthly precipitation from the Global Precipitation Climatology Centre (GPCC).

A systematic analysis is first performed of point correlation fields over the 21-year period between the winter NAO index and spring and summer NDVI, followed by an assessment of the vegetation response to precipitation and temperature conditions in winter, over two contrasting regions, namely the Iberian Peninsula and Northeastern Europe. Finally, the impact of NAO on vegetation dynamics over the two regions is evaluated by studying the corresponding annual cycles of NDVI and comparing their behaviour for years associated with opposite NAO phases.

Over the Iberian Peninsula there is strong evidence that positive (negative) values of winter NAO induce low (high) vegetation activity in the following spring and summer seasons. This feature is mainly associated with the impact of NAO on winter precipitation, together with the strong dependence of spring and summer NDVI on water availability during the previous winter. Northeastern Europe shows a different behaviour, with positive (negative) values of winter NAO inducing high (low) values of NDVI in spring, but low (high) values of NDVI in summer. This behaviour mainly results from the strong impact of NAO on winter temperature, associated with the critical dependence of vegetation growth on the combined effect of warm conditions and water availability during the winter season. Copyright (C) 2008 Royal Meteorological Society
\end{abstract}

KEY WORDS NDVI; vegetation cycle; NAO; climate impacts; Iberia; Northeastern Europe

Received 19 July 2007; Revised 15 November 2007; Accepted 24 December 2007

\section{Introduction}

Over the last two decades, continuous monitoring of vegetation from space has prompted new studies aiming to relate observed major global changes in vegetation (e.g. trends, variability and extremes) with changes in surface climatic variables, such as temperature and precipitation (Myneni et al., 1997; Hansen et al., 1999; Zhou et al., 2001). In particular, several groups have shown that the recorded temperature increase in the northern latitudes of $0.8^{\circ} \mathrm{C}$ in the last 25 years has been accompanied by a significant reduction in annual snow cover, induced by an earlier spring snowmelt (Groisman et al., 1994; Vinnikov et al., 1999). A longer active growing season has also been reported, as a result of an early spring start and delayed autumn ending (Bogaert et al., 2002; Shabanov et al., 2002). This change in the annual phenological cycle is associated with an

\footnotetext{
* Correspondence to: Ricardo M. Trigo, Centro de Geofísica da Universidade de Lisboa, Departamento de Física, Faculdade de Ciências, Univ. de Lisboa, Campo Grande, Ed C8, Piso 6, 1749-016 Lisboa, Portugal. E-mail: rmtrigo@fc.ul.pt
}

increase in photosynthetic activity of vegetation (Zhou et al., 2001), as detected from observed changes in the Normalised Difference Vegetation Index (NDVI). Although no evidence has been given that such changes in NDVI are related to the positive trend in atmospheric concentration of $\mathrm{CO}_{2}$ (Kaufmann et al., 2002), the global carbon cycle certainly has been affected (Keeling et al., 1996).

There is a strong need for long-term, large-scale studies aiming to assess the impact of atmospheric circulation variability on surface climate and related vegetation activity. In this respect special attention has been devoted to investigating relationships between vegetation dynamics and the North Atlantic Oscillation (NAO), which is the major pattern of atmospheric variability in the Northern Hemisphere (Hurrell, 1995). A review of the studies considered as especially relevant to the present work will be given in the next section. A number of them have naturally addressed the question of the relationship between NDVI and meteorological fields, namely temperature and precipitation. VicenteSerrano and Heredia-Laclaustra (2004) have adopted the 
climatological viewpoint and focused their attention on the Iberian Peninsula where the influence of winter NAO on the precipitation regime is especially prominent in the southwest region (Rodriguez-Puebla et al., 1998). They have shown the existence of a positive trend in annual vegetation productivity where the NAO influence is weaker, in strong contrast to the stable or negative trends that were detected in the areas located in the south of Iberia, where precipitation is mostly determined by NAO. However the authors pointed out the need for further studies, at finer temporal scales, namely at the monthly and seasonal ones.

Stöckli and Vidale (2004) have found that spring plant phenology over Europe is well correlated with the winter NAO index. Their study has focused on several geographical sub-domains of Europe that neither reflect any bio-geographical stratification nor any particular sensitivity to the NAO index. The Mediterranean and, in particular, the Iberian Peninsula was not included in the study because their analysis procedure required a large seasonal amplitude in the phenology. The aim of the present work is to fill the gap between the assessment made by land cover experts and by researchers that have looked at the problem from a climatological viewpoint. We will search for relationships between NAO and vegetation activity at the month and seasonal levels over Europe and look for regions where such activity presents a clear dependence on NAO both in spring and summer. We will then investigate how such dependence may be explained in terms of the impact of NAO on relevant surface climate variables, namely temperature and precipitation. We will pay special attention to the Iberian Peninsula and Northeastern Europe because of the distinctive vegetation response to precipitation and temperature. Finally, we will identify, which of the variables have a determinant role on vegetation activity of different regions and make an assessment on the role played by the variables in the annual cycle of vegetation activity.

Accordingly, the main goals of our work are the following:

1. To study the relation between vegetation phenology and NAO over Europe.

2. To characterise the vegetation response to precipitation and temperature in two contrasting areas of Europe, respectively Northeastern Europe and the Iberian Peninsula.

3. To assess the impact of NAO on the vegetative cycle in the two areas, and relate it to the different land cover types and their response to surface climate variability.

\section{Rationale}

NAO has been known for more than 80 years (Walker, 1924), but it was only in the 1970s that its prime importance as an atmospheric circulation mode of the Northern Hemisphere was recognized and became a subject of wide interest (e.g. van Loon and Rogers, 1978; Rogers, 1984; Barnston and Livezey, 1987). More recently, the work by Hurrell (1995) had a significant impact on the climatological community and was followed by an increasing number of studies, several of them pointing out the existence of links between the NAO index and the winter season precipitation in Western Europe and, in particular, over the Mediterranean basin (Hurrell, 1995; Qian et al., 2000; Trigo et al., 2002, 2004). The control exerted by NAO on the precipitation field over Europe is likely to be related to changes in the activity of North Atlantic storm tracks (Serreze et al., 1997; Trigo, 2006), and the relationship between NAO and precipitation has been used in longrange forecasting models for Iberia (e.g. Gámiz-Fortis et al., 2002; Rodríguez-Fonseca and Castro, 2002). The strong NAO-precipitation link is also likely to have an impact on vegetation greenness (Buermann et al., 2003). In this respect, the use of NDVI to characterise vegetation activity is especially appropriate in the framework of climatological studies, because of the current availability of long-term datasets ( $>20$ years, at present).

The NDVI was designed to capture the contrast between red and near-infrared reflection of solar radiation by vegetation, and is an indicator of the amount of green leaf area (Asrar et al., 1984; Myneni et al., 1995). Despite its simplicity, NDVI has been widely used in studies of vegetation phenology and interannual variability of vegetation greenness. Different authors have looked for relationships between global and regional NDVI and meteorological fields, pointing out the existence of time lags, namely with precipitation (Di et al., 1994; Buermann et al., 2003; Lotsch et al., 2003) and temperature (Buermann et al., 2003; Wang et al., 2003; Julien et al., 2006).

Relationships between NAO and diverse aspects of European vegetation dynamics have been addressed by various authors. D'Odorico et al. (2002) showed that spring phenology in the British Isles is influenced by NAO. Dates of leaf unfolding for a mean of nine plant species vary over a 40-day range, from approximately the spring equinox to the end of April. The Julian date of leaf unfolding is inversely correlated with the NAO phase, i.e. leaf unfolding occurs earlier under positive, and later under negative phases of NAO. Similar patterns are reported for Poland, Norway and Sardinia. D'Odorico et al. (2002) also found a strong NAO influence on the timing of the pollen season in Europe.

Cook et al. (2004) modelled the NAO-dependence of phenological variability in Europe, mediated by the NAO influence on synoptic scale winter temperature variability, and successfully reproduced observed patterns of growing degree-days over Europe. A projection of NAO trends 50 years into the future, based on climate change scenarios, indicated a sustained advance of the growing season start.

Stöckli and Vidale (2004) used advanced very high resolution radiometers (AVHRR) Pathfinder NDVI data, and found that spring phenology correlates well with anomalies in winter temperature and winter NAO index. They 
established the existence of trends towards an earlier onset and longer duration of the spring vegetation growing period, especially significant over Central Europe.

Vicente-Serrano and Heredia-Laclaustra (2004) analysed the relationship between the NAO index and vegetation productivity (represented by the annual integral of monthly AVHRR Pathfinder NDVI values) trends, for the Iberia Peninsula. Areas of stable or decreasing vegetation productivity were located in southern Iberia, where the NAO influence is stronger. Significant positive productivity trends occur in the north of the Peninsula, where the NAO influence on vegetation dynamics is weaker.

The present study relies on AVHRR NDVI data from the Global Inventory Modeling and Mapping Studies (GIMMS, http://gimms.gsfc.nasa.gov/) group (Brown et al., 2006), which incorporate more thorough and accurate corrections of orbital drift, radiometric degradation, and volcanic aerosol effects than those previously applied to the Pathfinder AVHRR Land (PAL) product, used in earlier works.

\section{Data}

As pointed out in the introduction, we will look for relations involving large-scale atmospheric variability, vegetation greenness and surface climate. Accordingly, the main sources of information consist of time-series of the NAO index, NDVI and, for surface climate, precipitation $(\mathrm{P})$ and brightness temperature $(\mathrm{T})$, which may be taken as a proxy for land surface temperature.

The NAO index used in this study is based on the one developed by the Climatic Research Unit (University of East Anglia, UK), which was originally defined, on a monthly basis, as the difference between the normalized surface pressure at Gibraltar, in the southern tip of the Iberian Peninsula and Stykkisholmur, in Iceland (Jones et al., 1997). For each year covering the 21year long period from 1982 to 2002, we have derived a late winter NAO index, defined as the average of the monthly values of January, February and March of the corresponding year. From now on, we will use the term NAO to refer to the three-monthly averaged index and any averaged quantity over January, February and March will be also identified by the subscript NAO (e.g. $\mathrm{P}_{\mathrm{NAO}}$ and $\mathrm{T}_{\mathrm{NAO}}$ ). The original time-series of winter monthly values of the NAO index presents a positive trend over the last 30 years. Therefore its distribution is dominated by positive values, leading to late winter averages above zero (Jones et al., 1997). Accordingly, we have normalized the derived time-series of NAO indices over the 21-year period (Figure 1) and therefore our three-monthly averages have zero mean and unit standard deviation between 1982 and 2002. We have also identified two classes of years, characterised by extreme NAO indices, respectively above the $3 \mathrm{rd}$ and below the 1 st quartiles. These two classes, respectively denoted by $\mathrm{NAO}^{+}$and $\mathrm{NAO}^{-}$, are represented, by open and black circles in Figure 1. It may be noted that the $\mathrm{NAO}^{+}$years

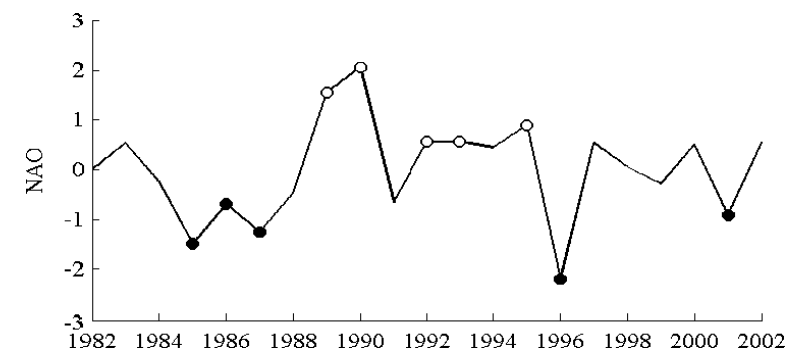

Figure 1. Interannual variability of normalized late winter NAO index over the 21-year long period (1982 to 2002). Open (black) circles indicate years characterised by NAO indices above (below) the $3 \mathrm{rd}$ (1st) quartile.

concentrate in the period from 1989 to 1995 , a feature of NAO that shows periodic non-stationary oscillations that may give rise to periods of several years of persistence of the NAO in one of its extreme phases (Pozo-Vazquez et al., 2001).

We also used monthly values of NDVI and channel 4 brightness temperature, at $8-\mathrm{km}$ resolution, from the AVHRR, as provided by GIMMS group (Brown et al., 2006). The pre-processing of satellite data involved cloud screening and calibration for sensor degradation and inter-sensor variations (Los, 1998). In particular, the data from April 1982 to December 1984 and from June 1991 to December 1993 were corrected to remove the effects of stratospheric aerosol from El Chichon and Mount Pinatubo eruptions (Tanré et al., 1992). Further details on the quality of the AVHRR dataset may be found in Kaufmann et al. (2000) and Zhou et al. (2001). Selected data are defined on a window covering the Eurasian and North Atlantic regions, from $23^{\circ} \mathrm{W}$ to $27^{\circ} \mathrm{E}$ and from $35^{\circ} \mathrm{N}$ to $75^{\circ} \mathrm{N}$ (Figure 2). Finally, we used monthly precipitation data from the Global Precipitation Climatology Centre (GPCC) (Rudolf and Schneider, 2005). Selected data are defined on a $0.5^{\circ}$ latitude by $0.5^{\circ}$ longitude grid and cover the same period and window as the satellite data.

For each grid point, we computed spring and summer values of NDVI, T and P, respectively defined as the average of March, April and May and of June, July and August. Spring and summer values of a given quantity will be respectively denoted by the subscripts SPR and SUM. For instance, Figure 2 presents the spatial distribution of the temporal averages of $\mathrm{NDVI}_{\mathrm{SPR}}$ (left panel) and $\mathrm{NDVI}_{\mathrm{SUM}}$ (right panel) for the considered period (1982-2002).

\section{Results}

4.1. NAO and vegetation greenness

Figure 3 displays the spatial patterns, over the selected European window, of point correlation values of NAO versus $\mathrm{NDVI}_{\mathrm{SPR}}$ and $\mathrm{NAO}$ versus $\mathrm{NDVI}_{\mathrm{SUM}}$ for the 21year period. Results show a positive correlation region over Central Europe for spring (left panel), the highest 

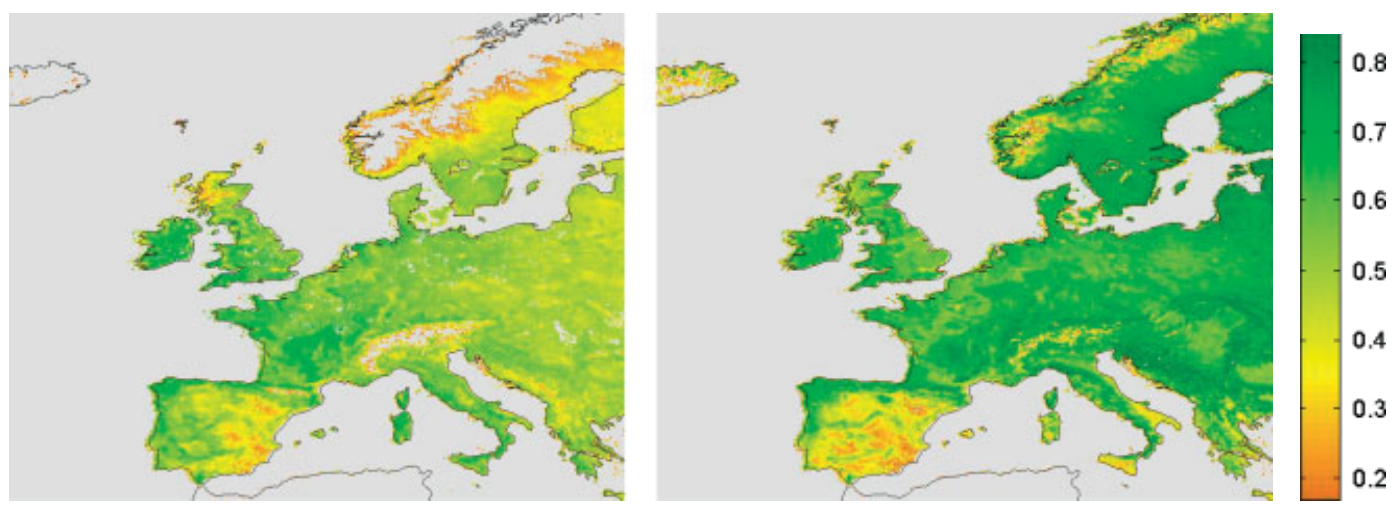

Figure 2. Temporal averages of NDVISPR (left panel) and NDVISUM (right panel) for the period from 1982 to 2002 over the selected area covering Eurasia and the North Atlantic.

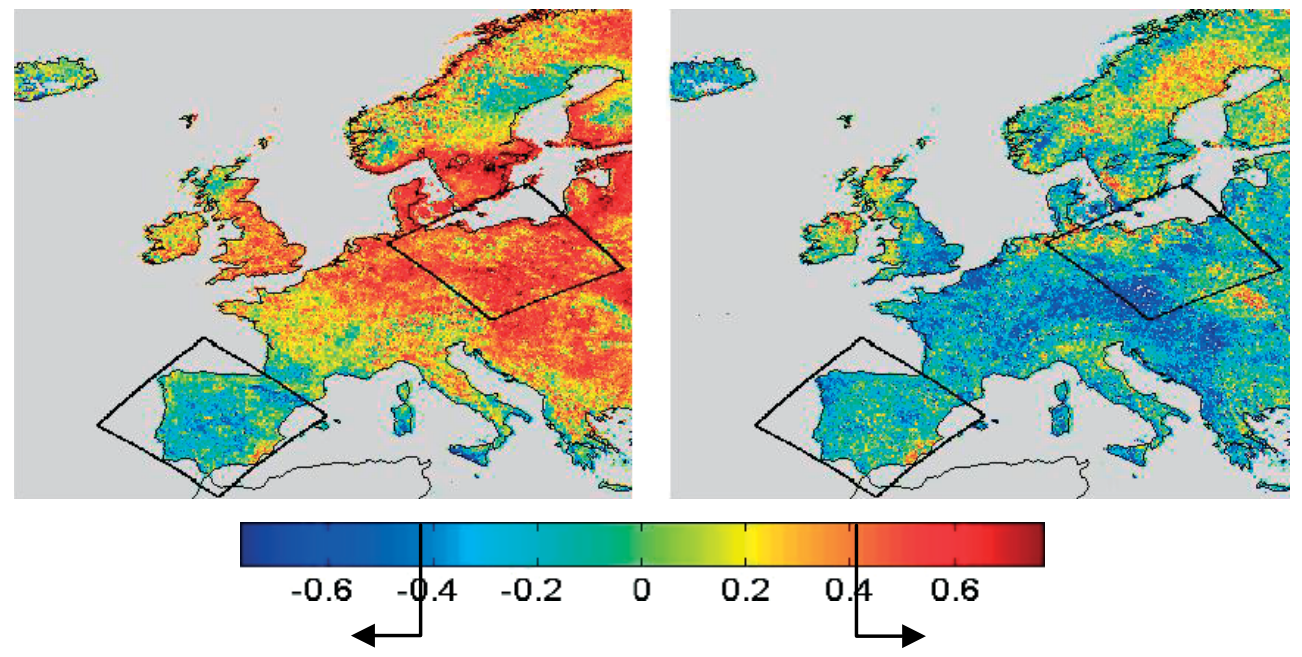

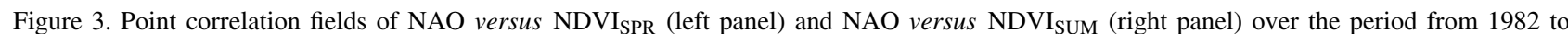
2002. Black frames identify the Northeastern Europe and the Iberian Peninsula. The colorbar shows values of correlation and the two arrows indicate the ranges that are significant at the $5 \%$ level.

values (between 0.6 and 0.8 ) spreading around the northeastern region. The largest negative correlation regions are located over the Iberian Peninsula and Iceland, some values reaching as low as -0.8 . It may be noted that obtained patterns are consistent with the recent findings by other authors, at both the global (Buermann et al., 2003) and the regional (e.g. Vicente-Serrano and Heredia-Laclaustra, 2004) scales. However, we have based our analysis on a much finer spatial resolution than Buermann et al. (2003) and, despite the overall consistency, some differences do exist, namely the higher values of correlation that we obtained over the northeastern sector.

In the case of summer (Figure 3, right panel), the correlation field presents negative values over almost all Central-Eastern Europe. This pattern is also consistent with the finding of Buermann et al. (2003), but their maximum core is located towards the northern Black Sea area, whereas ours is confined to the upper Danube region.

The contrasting behaviour of north-eastern and southwestern regions of Europe is worth being further investigated. For this purpose we have selected two regions, namely Northeastern Europe (hereafter NE) and the Iberian Peninsula (hereafter IB). These two regions are identified by black frames in Figure 3 and it may be noted that selection was made in such a way to obtain an amount of land pixels of the same order in the two regions, respectively 9639 over NE and 9080 over IB. Both NE and IB show fairly coherent values of correlation of NAO versus NDVI for both spring and summer. It is also apparent that over IB, NAO is anti-correlated with vegetation greenness both in spring and summer, whereas over NE the correlation is positive in spring and predominantly negative in summer. During spring, the distribution of correlation values over NE presents a median value about 0.5 , whereas the distribution over IB has a median of -0.2 and spans a wide range of negative values, reaching as low as -0.7 . During summer, both areas exhibit distributions with similar medians about -0.2 , but the lower dispersion is now observed over IB.

The distinctive behaviour of the Iberian Peninsula and Northeastern Europe is to be expected and reflects, on the one hand, the different response of the annual variability of meteorological parameters of the two areas 
to large-scale atmospheric variability associated to the NAO mode; on the other hand, it reflects the different responses of vegetation to atmospheric variability, in particular changes induced by temperature and precipitation in the annual cycle of heat and moisture. For instance in the case of wheat that is grown in both regions, water is the main limiting factor for growth in IB (Gouveia and Trigo, 2008), whereas it is temperature that limits its growth in NE. The following section will be devoted to characterising the influence of the NAO mode over two atmospheric parameters relevant to vegetation activity, namely surface temperature and precipitation. The analysis will focus on the Iberian Peninsula and Northeastern Europe and the different roles played by temperature and precipitation in the two sub-areas will be emphasized. This section is followed by a final one dedicated to the analysis of the annual cycles of the main land cover types over the two areas and of their different responses to the NAO mode of atmospheric variability.

It may be noted at this point that climate conditions are not the only factor that acts on vegetation dynamics; the nature and quality of the plant substrate, the over-use of agriculture land and the employment of irrigation are important factors linked to the human influence that may disturb the relationship between atmospheric parameters and vegetation activity. With the aim of isolating the effect of natural atmospheric variability, as represented by the NAO, on vegetation dynamics from factors related to the human influence, we have compared the NDVI fields over IB and NE for two years associated to extreme NAO indices. Figure 4 shows a comparison of $\mathrm{NDVI}_{\mathrm{SPR}}$ for the two chosen years, i.e. $1986\left(\mathrm{NAO}^{-}\right)$and $1995\left(\mathrm{NAO}^{+}\right)$. In the case of

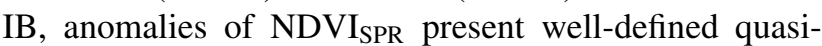
meridional dipoles of opposite signs in 1986 (upper left panel) and 1995 (middle left panel). The southern anomaly centre is particularly intense, positive (negative) anomalies being observed in spring 1986 (1995). The dipolar structure is especially apparent when differences are computed between 1995 and 1986 (lower left panel). In the case of NE (right panels) large patterns of negative (positive) anomalies of $\mathrm{NDVI}_{\mathrm{SPR}}$ may be observed in 1986 (1995). Observed anomalies are particularly intense in $1986\left(\mathrm{NAO}^{-}\right)$and this feature is well apparent when
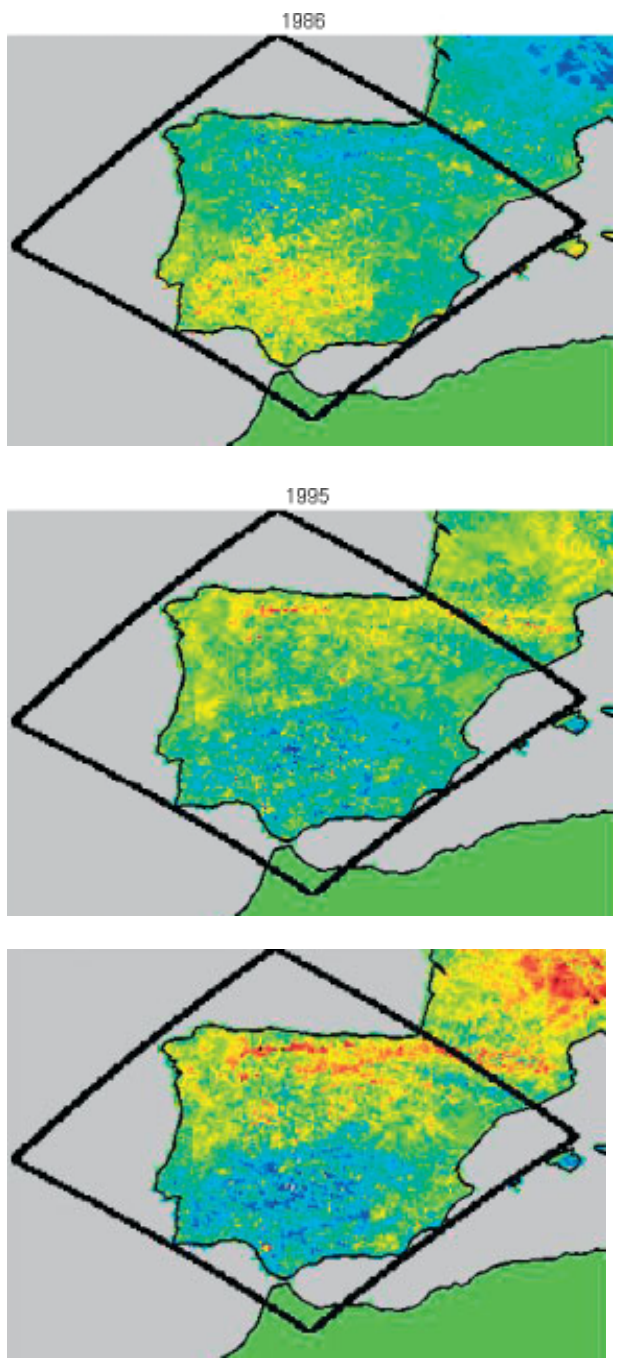

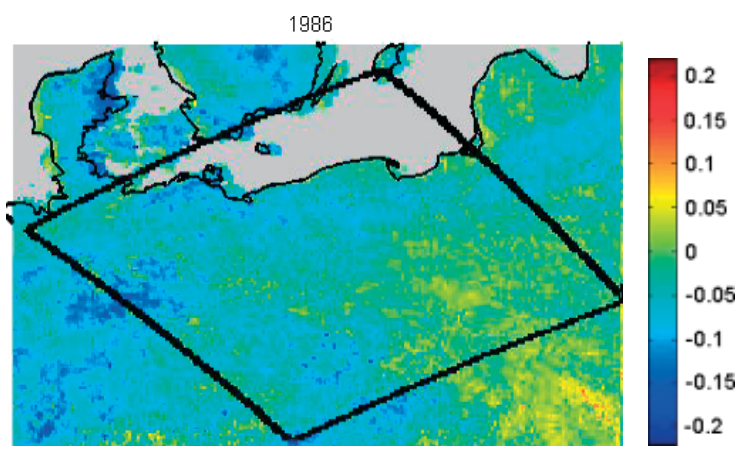

1995
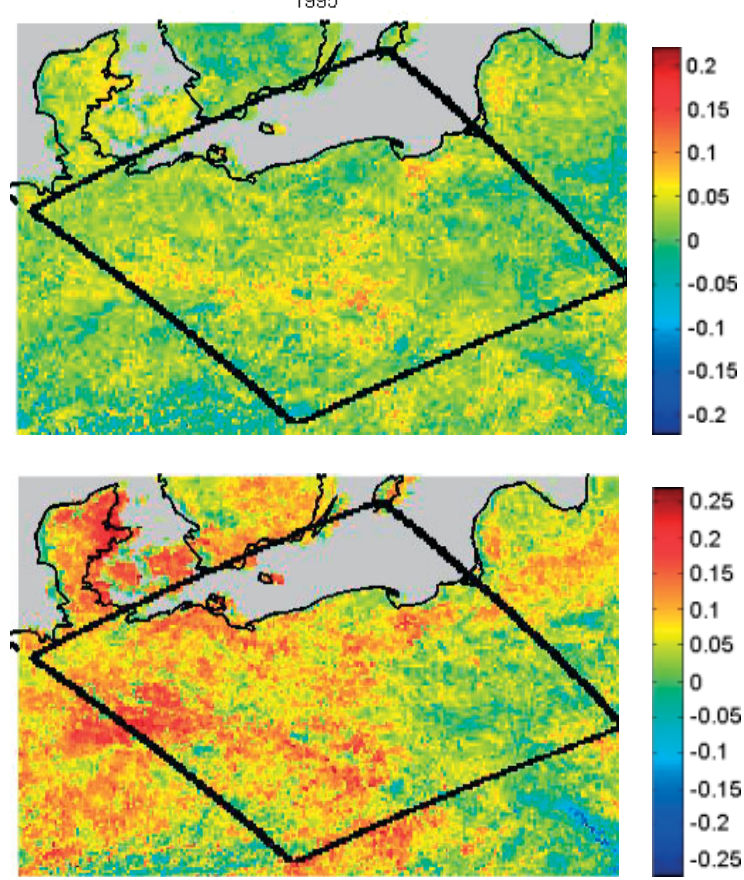

Figure 4. Seasonal anomalies of NDVI $\mathrm{SPR}_{\text {f }}$ for $1986\left(\mathrm{NAO}^{+}\right), 1995\left(\mathrm{NAO}^{-}\right)$and differences between 1995 and 1986 (upper, middle and lower panels, respectively) for the IB and NE regions (left and right panels respectively). 
analysing differences between 1995 and 1986 (lower right panel).

\subsection{NAO and annual variability of atmospheric parameters}

Figure 5 shows spatial patterns over the selected European window of point correlation fields between the NAO index and the contemporaneous late winter means of surface temperature and precipitation, i.e. NAO versus $\mathrm{T}_{\mathrm{NAO}}$ and $\mathrm{NAO}$ versus $\mathrm{P}_{\mathrm{NAO}}$. Obtained patterns display the well known response to the NAO signal, of temperature and precipitation over Europe (Hurrell, 1995; Trigo et al., 2002). In the case of temperature, a region of positive values over Central and Eastern Europe is well apparent (Trigo et al., 2002). Albeit less intense, negative values of correlation may also be identified over the Iberian Peninsula. For precipitation, a well-developed meridional dipolar structure is conspicuous over Europe, delimiting two well-defined zonal bands of positive and negative correlation values, which spread over Northern Europe and along the Mediterranean regions, respectively. These results are in good agreement with those obtained by several authors (e.g. Saénz et al., 2001; Castro-Díez et al., 2002) who have pointed out that the connection between $\mathrm{NAO}$ and Iberian temperature is not as clear-cut as in the case of precipitation. Finally, the intense east-west precipitation gradients observed in southern Norway/Sweden as well as over Ireland and England is worth being point out. These strong precipitation gradients over such short distances are associated with the mountain ranges located in the western sector of these three regions and highlight the lee effect.

Although it is known that the impact of NAO on temperature and precipitation described above is especially prominent in winter (e.g. Trigo et al., 2004; VicenteSerrano and Heredia-Laclaustra, 2004), such behaviour contrasts with that obtained for vegetation activity (Figure 3), where the impact of NAO is clearly apparent both in spring and summer (i.e. NAO versus $\mathrm{NDVI}_{\mathrm{SPR}}$ and NAO versus NDVI $_{\text {SUM }}$ ). This gives a strong indication that special attention must be devoted to the relationship between late winter temperature and late winter precipitation, with vegetation greenness in the following spring and summer seasons.

Since we are particularly interested in pixels characterised by the strong influence of NAO on vegetation activity, we will restrict our analysis to IB and NE (as identified in Figure 3), and will focus on those pixels that exhibit the highest (lowest) values of positive (negative) correlations of NDVI SPR $_{\text {and NDVI }}$ SUM with NAO. Henceforth, they will be called North Atlantic oscillation high correlation pixels (NHCP).

As pointed out in the previous section, vegetation greenness over the Iberian Peninsula is negatively correlated with NAO, both in spring and summer. Accordingly, we selected, for each one of the two seasons, the 500 highest NHCP. In the case of NE, NHCP were predominantly correlated with NDVI in spring and anticorrelated in summer. Therefore we selected the 500 pixels with the highest (lowest) values of positive (negative) correlation in spring (summer). Figures 6 and 7 show the geographical distribution of the NHCP for spring and summer, respectively over IB and NE. Information about the land cover type associated to each pixel is also provided, as obtained from the Global Land Cover 2000 (GLC2000) database (http://wwwgvm.jrc.it/glc2000). Table I shows descriptive statistics of the NHCP associated with the two most common types of vegetation namely in what respects to the distribution of NDVI anomalies for two classes of years, characterised by extreme $\mathrm{NAO}$ indices, i.e. the $\mathrm{NAO}^{+}$and $\mathrm{NAO}^{-}$, as described in Section 3. NDVI anomalies in a given pixel are defined as differences from the respective 21year mean (1982-2002) and the two considered classes of years. For each area and season the statistical distributions of NDVI anomaly values for the two classes of years $\left(\mathrm{NAO}^{+}\right.$and $\left.\mathrm{NAO}^{-}\right)$and the two types of vegetation cover are characterised by means of the respective

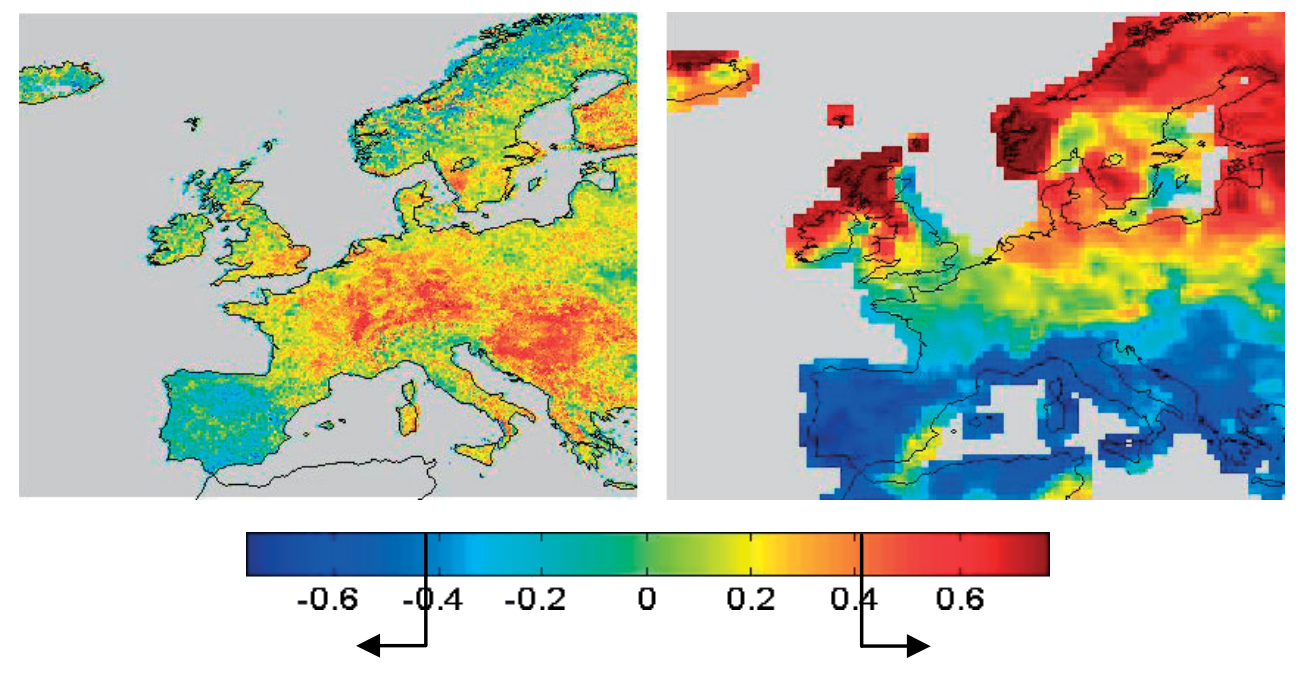

Figure 5. Point correlation fields of NAO versus $\mathrm{T}_{\mathrm{NAO}}$ (left panel) and NAO versus $\mathrm{P}_{\mathrm{NAO}}$ (right panel) over the period from 1982 to 2002 . The colorbar shows values of correlation and the two arrows indicate the ranges that are significant at $5 \%$ level. 

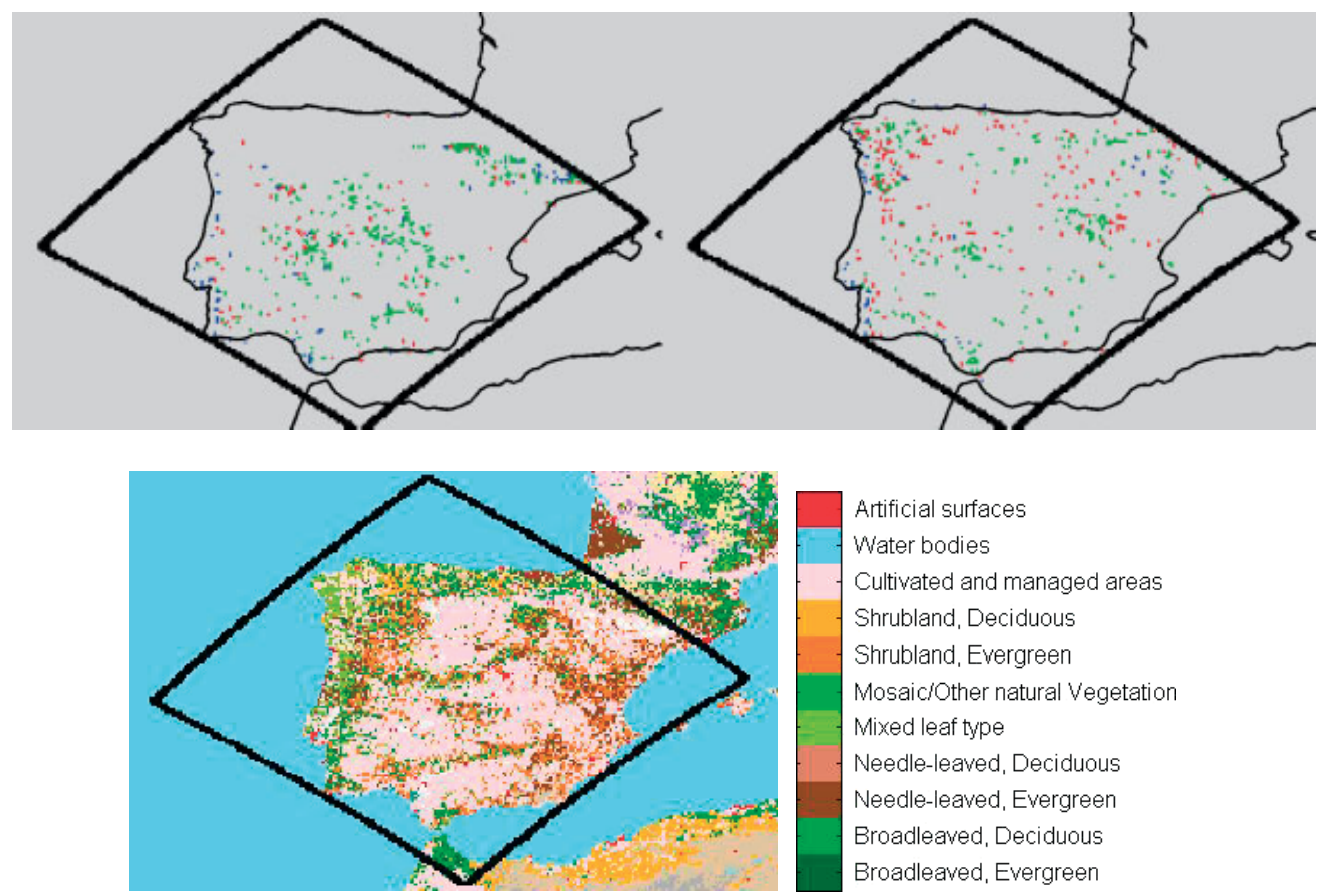

Artificial surfaces

Water bodies

Cultivated and managed areas

Shrubland, Deciduous

Shrubland, Evergreen

Mosaic/Other natural Vegetation

Mixed leaf type

Needle-leaved, Deciduous

Needle-leaved, Evergreen

Broadleaved, Deciduous

Broadleaved, Evergreen

Figure 6. Geographical distribution of NAO High Correlation Pixels (NHCP) sets of selected pixels over IB based on the strong values of correlation of NDVI SPR $_{\text {(left panels) and NDVI }}$ SUM (right panels) with NAO. Red, green and blue pixels are respectively associated to forest and shrubland, cultivated areas and other types of vegetation cover. Bottom panel shows the GLC2000 classification for Iberia.
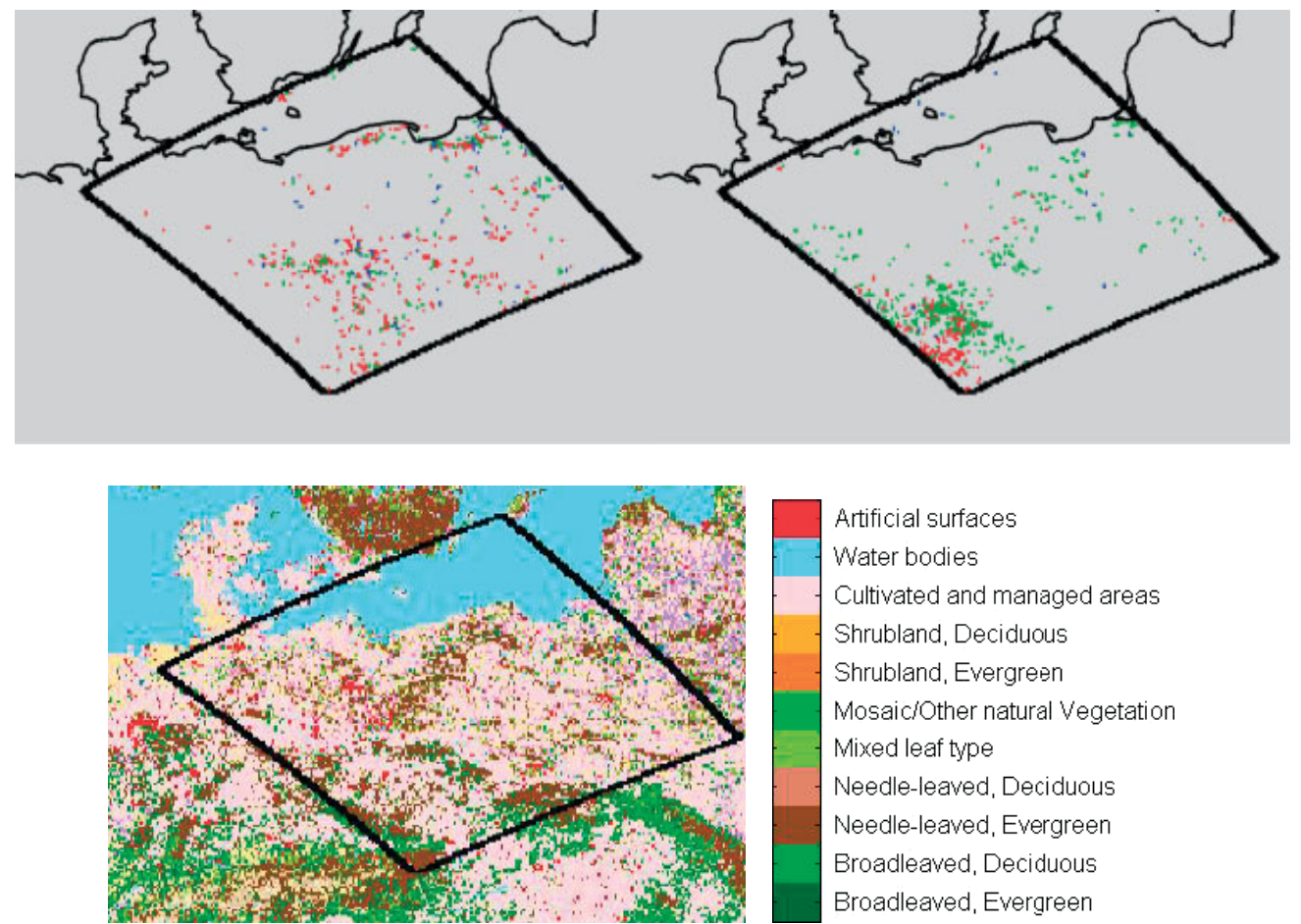

Artificial surfaces

Water bodies

Cultivated and managed areas

Shrubland, Deciduous

Shrubland, Evergreen

Mosaic/Other natural Vegetation

Mixed leaf type

Needle-leaved, Deciduous

Needle-leaved, Evergreen

Broadleaved, Deciduous

Broadleaved, Evergreen

Figure 7. As in Figure 6 but respecting to NHCP over NE. Red, green and blue pixels are respectively associated to needle-leaved, evergreen, cultivated and other types of vegetation cover.

median (Q2), first and third quartiles (Q1 and Q3), and percentiles 1 and 99 (P1 and P99).

As expected, there are marked differences in the obtained distributions of NDVI anomalies for $\mathrm{NAO}^{+}$and $\mathrm{NAO}^{-}$classes for a given type of vegetation, in a given season, over a given region. For instance, it is worth noting that there is no class overlap when restricting to median values between P1 and P99. This feature was taken into account in Figures 8 and 9, where a given year is characterised by its median value.

Differences in the distribution of types of vegetation are also conspicuous for the two regions and the two seasons. In the case of the Iberian Peninsula, almost two thirds $(64 \%)$ of the NHCP correspond to areas 
Table I. Descriptive statistics of the distributions of NDVI anomalies for NAO High Correlation Pixels (NHCP) associated to the two most important vegetation types as found in the cases of spring and summer over IB and NE. P1, Q1, Q2, Q3 and P99 respectively denote percentile one, the first quartile, the median, the third quartile and percentile 99 . Percent figures in parenthesis below the types of vegetation indicate the fraction of pixels of the considered NHCP associated to that type.

IB

\begin{tabular}{|c|c|c|c|c|c|c|c|c|c|c|}
\hline \multicolumn{11}{|c|}{ Spring } \\
\hline & \multicolumn{5}{|c|}{ Forest and shrubland $(17 \%)^{\mathrm{a}}$} & \multicolumn{5}{|c|}{ Cultivated $(64 \%)$} \\
\hline & $\mathrm{P} 1$ & Q1 & Q2 & Q3 & P99 & P1 & Q1 & Q2 & Q3 & P99 \\
\hline $\mathrm{NAO}^{+}$ & -0.049 & -0.030 & -0.021 & -0.013 & 0.002 & -0.080 & -0.041 & -0.031 & -0.022 & -0.004 \\
\hline $\mathrm{NAO}^{-}$ & 0.004 & 0.015 & 0.024 & 0.033 & 0.066 & 0.003 & 0.019 & 0.027 & 0.038 & 0.071 \\
\hline \multicolumn{11}{|c|}{ Summer } \\
\hline & \multicolumn{5}{|c|}{ Forest and shrubland $(29 \%)^{\mathrm{b}}$} & \multicolumn{5}{|c|}{ Cultivated $(47 \%)$} \\
\hline & P1 & Q1 & Q2 & Q3 & P99 & $\mathrm{P} 1$ & Q1 & Q2 & Q3 & P99 \\
\hline $\mathrm{NAO}^{+}$ & -0.053 & -0.031 & -0.023 & -0.017 & 0.005 & -0.066 & -0.036 & -0.026 & -0.014 & 0.000 \\
\hline $\mathrm{NAO}^{-}$ & -0.001 & 0.011 & 0.016 & 0.022 & 0.039 & 0.003 & 0.012 & 0.018 & 0.025 & 0.054 \\
\hline \multicolumn{11}{|c|}{$\mathrm{NE}$} \\
\hline \multicolumn{11}{|c|}{ Spring } \\
\hline & \multicolumn{5}{|c|}{ Needle-leaved Evergreen $(47 \%)^{\mathrm{c}}$} & \multicolumn{5}{|c|}{ Cultivated $(25 \%)$} \\
\hline & P1 & Q1 & Q2 & Q3 & P99 & $\mathrm{P} 1$ & Q1 & Q2 & Q3 & P99 \\
\hline $\mathrm{NAO}^{+}$ & 0.011 & 0.027 & 0.033 & 0.041 & 0.071 & 0.009 & 0.026 & 0.033 & 0.044 & 0.060 \\
\hline $\mathrm{NAO}^{-}$ & -0.084 & -0.054 & -0.043 & -0.035 & -0.014 & -0.072 & -0.055 & -0.045 & -0.037 & -0.010 \\
\hline \multicolumn{11}{|c|}{ Summer } \\
\hline & \multicolumn{5}{|c|}{ Needle-leaved Evergreen $(27 \%)^{\mathrm{d}}$} & \multicolumn{5}{|c|}{ Cultivated $(63 \%)$} \\
\hline & $\mathrm{P} 1$ & Q1 & Q2 & Q3 & P99 & $\mathrm{P} 1$ & Q1 & Q2 & Q3 & P99 \\
\hline $\mathrm{NAO}^{+}$ & -0.059 & -0.037 & -0.028 & -0.021 & -0.008 & -0.068 & -0.039 & -0.030 & -0.022 & -0.005 \\
\hline $\mathrm{NAO}^{-}$ & 0.006 & 0.020 & 0.025 & 0.032 & 0.056 & 0.009 & 0.022 & 0.027 & 0.034 & 0.052 \\
\hline
\end{tabular}

${ }^{a}$ Includes $14 \%$ of needle-leaved evergreen, $26 \%$ of broadleaved deciduous and $60 \%$ of Shrubland.

${ }^{\mathrm{b}}$ Includes $31 \%$ of needle-leaved evergreen, $25 \%$ of broadleaved deciduous and $44 \%$ of Shrubland.

${ }^{\mathrm{c}}$ Includes $12 \%$ of needle-leaved evergreen and $88 \%$ de broadleaved deciduous.

${ }^{\mathrm{d}}$ Includes $35 \%$ of needle-leaved evergreen and $65 \%$ de broadleaved deciduous.

of spring crops and about one sixth (17\%) are forests and shrublands. The relative proportion of the two types undergoes a significant change in summer, when a strong decrease may be observed in the difference between the fraction of NHCP belonging to the two types (29\% to forest and shrubland, and $47 \%$ to cultivated areas). In the case of NE, there is a dramatic change from spring to summer between the distributions of NHCP of the two types of vegetation; the predominance in spring of forest and shrubland (62\%) over cultivated areas $(25 \%)$ gives way, during the summer, to a predominance of NHCP representing agricultural crops $(63 \%)$, over those representing forests and shrublands $(27 \%)$.

The above results may be viewed in terms of the distinct responses of the various vegetation types to moisture and heat conditions prevailing during the previous winter.
These conditions, in turn, are determined by the nature of the relationships between the surface annual variability of atmospheric parameters, $\mathrm{P}_{\mathrm{NAO}}$ and $\mathrm{T}_{\mathrm{NAO}}$, and the different phases $\left(\mathrm{NAO}^{+}\right.$and $\mathrm{NAO}^{-}$) of the NAO atmospheric mode. Figures 8 and 9 show scatterplots, for IB and NE, respectively, of spring and summer anomalies of vegetation greenness against winter anomalies of temperature and precipitation. Each dot represents a pair of median values of a given set of selected $500 \mathrm{NHCP}$, for a given year of the considered period (1982-2002), of winter anomalies of $\mathrm{P}_{\mathrm{NAO}}$ (left panels) and $\mathrm{T}_{\mathrm{NAO}}$ (right panels) versus anomalies of $\mathrm{NDVI}_{\mathrm{SPR}}$ (upper panels) and $\mathrm{NDVI}_{\text {SUM }}$ (lower panels). Years belonging to the subset of $\mathrm{NAO}^{+}\left(\mathrm{NAO}^{-}\right)$are marked in dark (light) grey and the variability of the NHCP is characterised by means of horizontal and vertical bars indicating the respective interquartile ranges. 

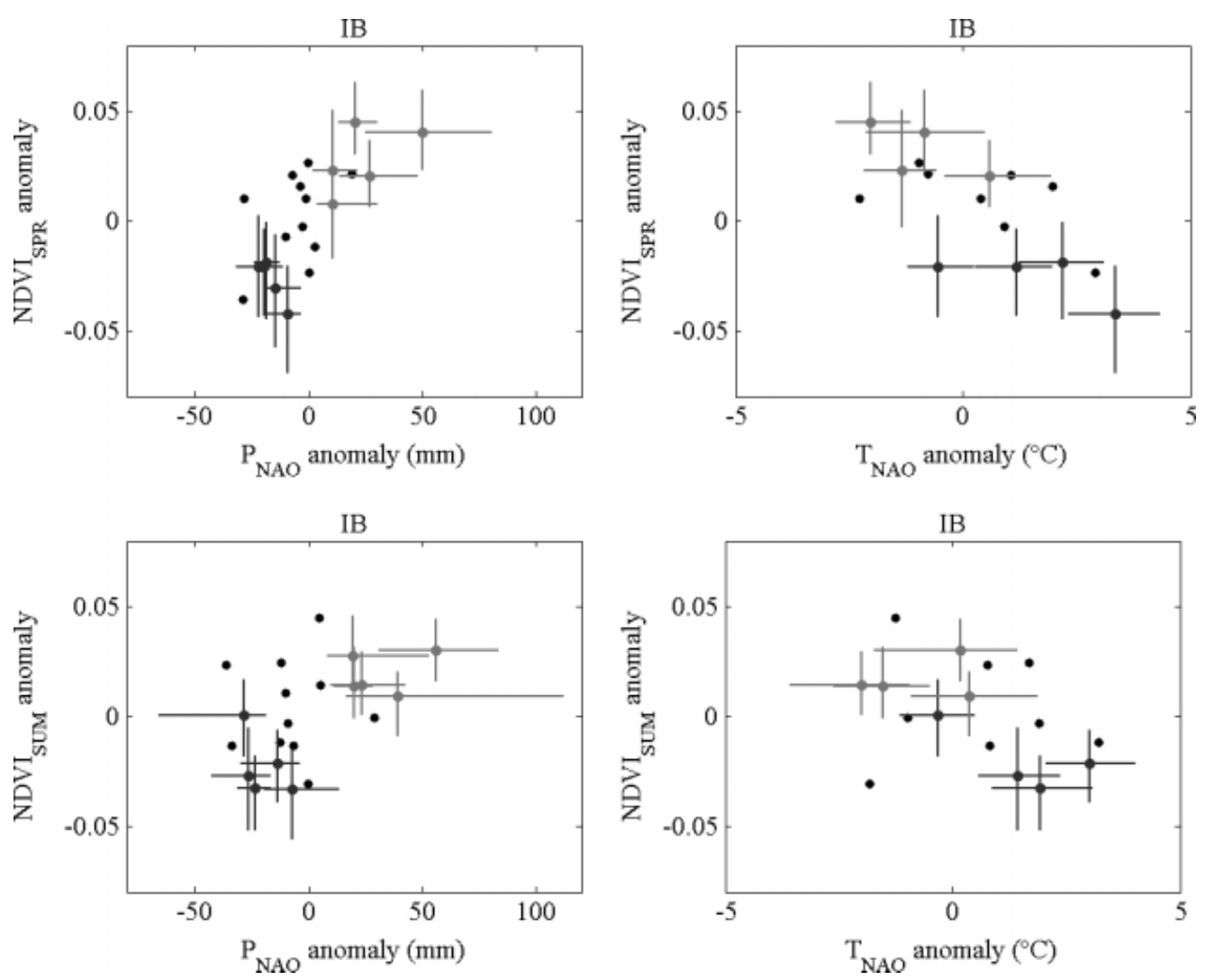

Figure 8. Dispersion diagrams of $\mathrm{NDVI}_{\mathrm{SPR}}$ (upper panels) and $\mathrm{NDVI}_{\mathrm{SUM}}$ (lower panels) versus $\mathrm{P}_{\mathrm{NAO}}$ (left panels) and $\mathrm{T}_{\mathrm{NAO}}$ (right panels) for NAO High Correlation Pixels (NHCP) over IB. Each dot represents a pair of median values of a given set of selected 500 pixels, for a given year of the considered period (1982-2002). Years that belong to the subset of $\mathrm{NAO}^{+}\left(\mathrm{NAO}^{-}\right)$are marked in dark (light) grey and the respective variability is characterised by means of horizontal and vertical bars indicating the interquartile ranges.
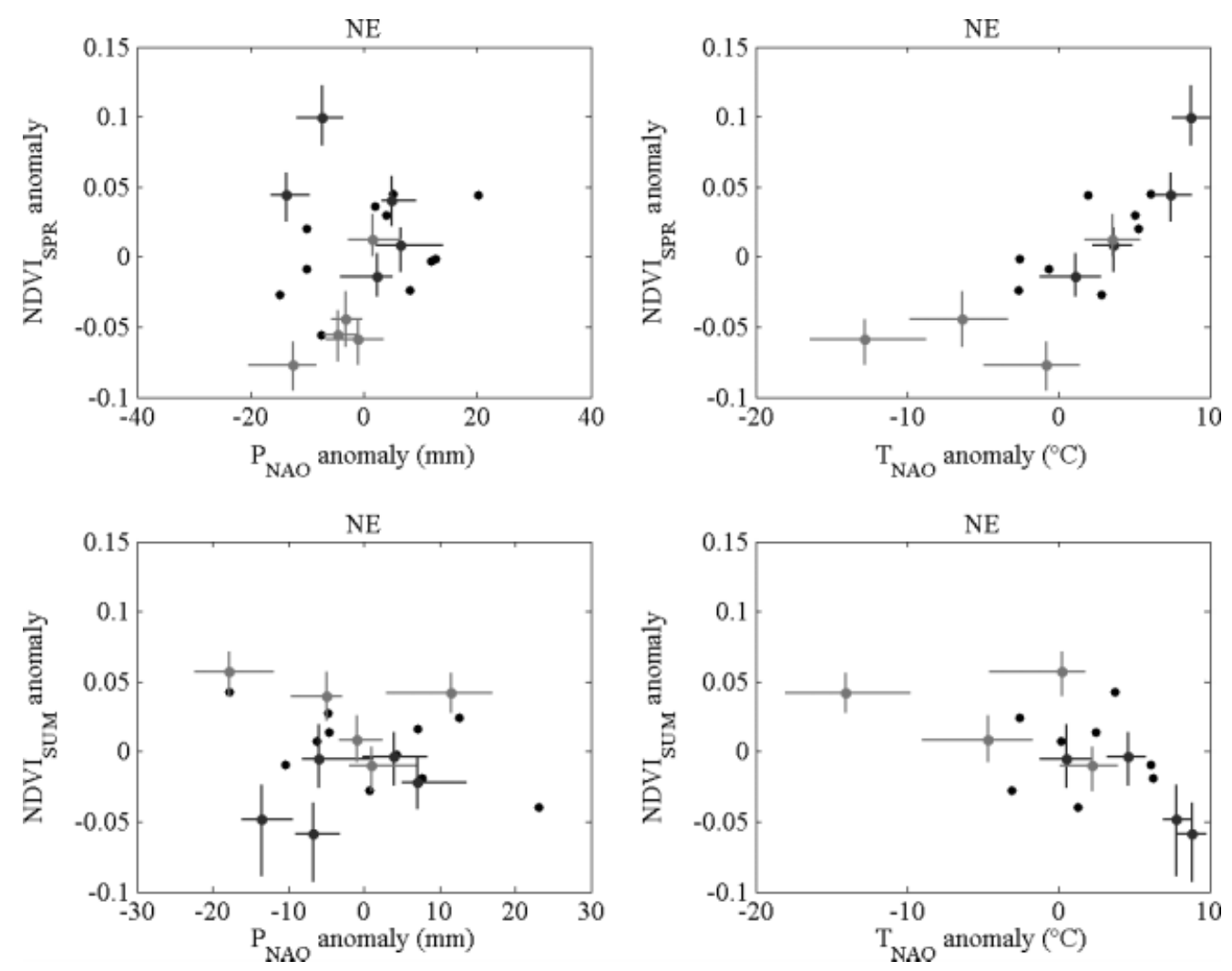

Figure 9. As in Figure 8, but respecting to NE. 

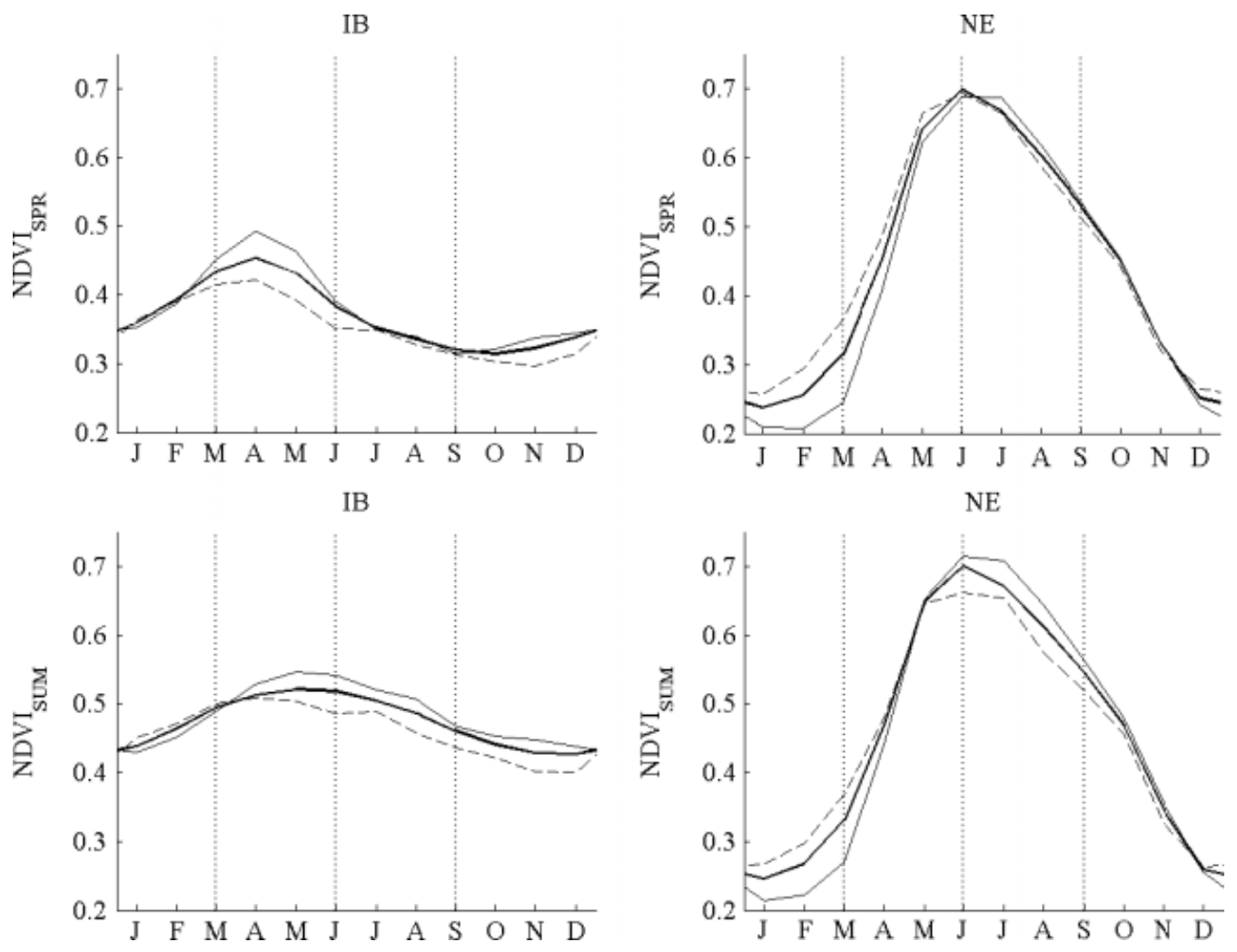

Figure 10. Annual cycles of monthly values of NDVI for NAO High Correlation Pixels (NHCP), for spring (upper panel) and summer (lower panel), over IB (left panel) and NE (right panel). The annual cycles of average NDVI values for the entire period (1982-2002) are represented by thick solid lines, whereas the annual cycles of averages for the $\mathrm{NAO}^{-}\left(\mathrm{NAO}^{+}\right)$subsets are identified by the thin solid (dashed) curves

Vertical dashed curves delimit the season of the year.
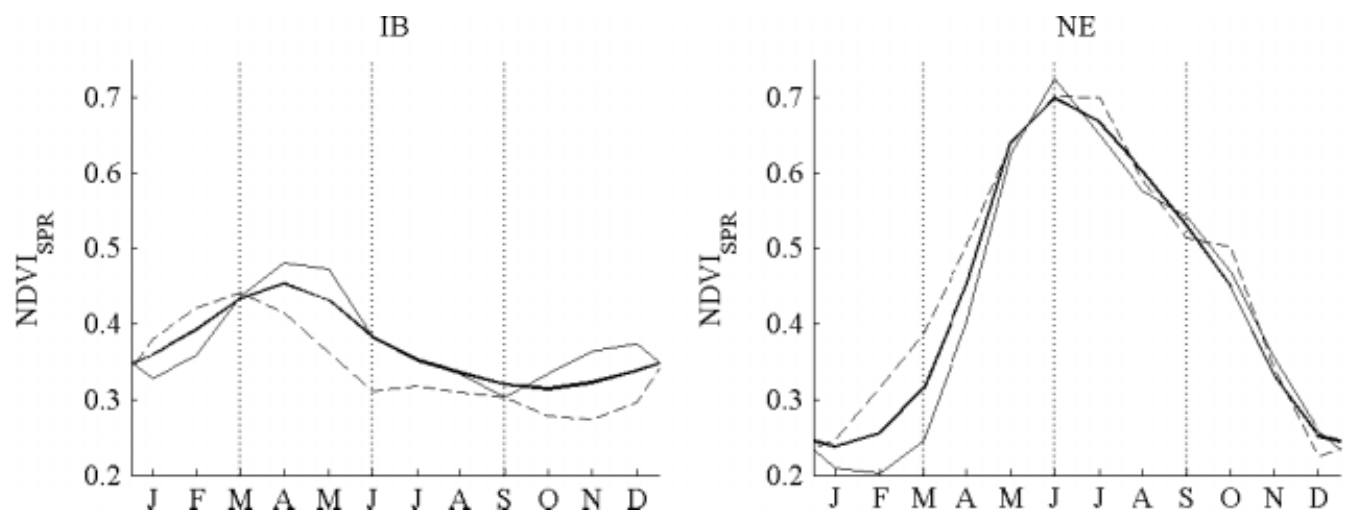

Figure 11. As in Figure 10, but restricting to the annual cycles of NDVI for the individual years of $1986\left(\mathrm{NAO}^{-}\right)$and $1995\left(\mathrm{NAO}^{+}\right)$, respectively represented by the dashed and the solid lines.

The Iberian Peninsula (Figure 8) shows a similar spring and summer vegetation response to precipitation in (left panels), i.e. an increase (decrease) of vegetation greenness for $\mathrm{NAO}^{-}\left(\mathrm{NAO}^{+}\right)$years. In both seasons there is less variability of precipitation in the set of $\mathrm{NAO}^{+} \mathrm{NHCP}$, in comparison with $\mathrm{NAO}^{-}$, especially in the spring. A slight dependence of vegetation greenness on temperature is also apparent in the case of spring, with NVDI ${ }_{\text {SPR }}$ median values showing a tendency to decrease from $\mathrm{NAO}^{-}$to $\mathrm{NAO}^{+}$. It may be noted that the obtained stronger dependence of vegetation on precipitation than on temperature is consistent with the already pointed out fact that over the Iberian Peninsula the influence of NAO is particularly strong on the precipitation regime, whereas the relationship between NAO and temperature is less clear. In the case of NE (Figure 9) there is a marked dependence of vegetation greenness on winter temperature, but the nature of such dependence is reversed from spring to summer. In the first case, $\mathrm{NDVI}_{\mathrm{SPR}}$ shows a strong increase from $\mathrm{NAO}^{-}$to $\mathrm{NAO}^{+}$, whereas a sharp decrease is observed for summer. The lower variability of temperature in the set $\mathrm{NHCP}$ for $\mathrm{NAO}^{+}$is again evident, when compared with the corresponding set for $\mathrm{NAO}^{-}$. Concerning winter precipitation, no effects are apparent 
on vegetation greenness for both spring and summer. Finally, the differences in magnitude of the impacts of NAO on precipitation and temperature in IB and NE is worth being emphasised; the impact on precipitation (temperature) is three times larger over IB (NE) than the corresponding impact over NE (IB), a feature that is in good agreement with the found dependences of NDVI on precipitation (temperature) over IB (NE). This is to be expected, since vegetation growth is much more waterlimited in IB than in NE.

\subsection{The NAO role on the vegetative cycle}

The striking differences that were obtained in the response of vegetation to moisture and heat conditions and to anomalies in $\mathrm{P}_{\mathrm{NAO}}$ and $\mathrm{T}_{\mathrm{NAO}}$ associated to the NAO atmospheric mode, warrant further analysis of the NDVI annual cycle for the NHCP over IB and NE. Figure 10 shows the annual cycles of NDVI monthly values for the $\mathrm{NHCP}$, for spring (upper panels) and summer (lower panels), over IB (left panels) and NE (right panels). The annual cycles of mean NDVI for the entire period (1982-2002) are represented by thick solid lines, whereas the annual cycles of averages for the $\mathrm{NAO}^{-}\left(\mathrm{NAO}^{+}\right)$subsets are identified by the thin solid (dashed) curves.

In the case of IB, the most interesting feature for both spring and summer (Figure 10, left panels) is that the highest impact of NAO is observed to occur during the periods of the year characterised by more intense vegetation activity (Ji and Peters, 2003), i.e. around April (June) in the case of the NHCP for spring (summer). During spring, two thirds of the NHCP (Table I) correspond to cultivated areas that mainly consist of crops adapted to the relatively dry Iberian conditions. Owing to the generally observed high temperatures, vegetation has a short growth cycle that starts as soon as water is available, a situation that is especially favoured by $\mathrm{NAO}^{-}$ This is especially apparent in Figure 11 (left panel) where the annual cycles of NDVI are compared for the years of $1986\left(\mathrm{NAO}^{-}\right)$and $1995\left(\mathrm{NAO}^{+}\right)$that were chosen because of being associated to extreme NAO indices. In the case of summer, the vegetation that is most affected by NAO initiates its growing period late in the year and therefore the response to precipitation tends to extend late in the year.

In the case of NE (Figure 10, right panels), the annual cycles present characteristics that are very different from those observed over IB. The impact of NAO is especially conspicuous during the first months of the year, suggesting that green vegetation growth tends to occur early and intensively, due to the combined effect of warm conditions, especially of the former, since water availability is seldom a problem in NE. This contrast in the response of vegetation during the early months is also well apparent in Figure 11 (right panel) where the years of $1986\left(\mathrm{NAO}^{-}\right)$and $1995\left(\mathrm{NAO}^{+}\right)$are compared. The distinct behaviour of vegetation in spring (Figure 10, upper panel) and summer (lower panel) is also worth pointing out. In the case of the spring, the NAO impact is almost negligible, whereas in the case of the summer the growth of vegetation is enhanced under $\mathrm{NAO}^{-}$ conditions. This is to be expected, since snow melt is expected to occur later in the year, due to the lower winter temperature. Accordingly, vegetation growth will be reduced in spring, getting delayed until summer, when solar radiation availability increases (Blenckner and Hillebrand, 2002; Menzel, 2003; Wang and You, 2004).

\section{Conclusions}

We analysed the relationship between the NAO atmospheric mode and vegetation activity (NDVI) over the two contrasting regions of Iberia and Northeastern Europe. As expected the behaviour of vegetation reflects the different response of surface climate to large-scale atmospheric variability associated to the NAO mode. A systematic analysis was performed over two contrasting regions of Europe, namely IB and NE. Over IB there is strong evidence that positive (negative) values of winter NAO induce low (high) vegetation activity in the following spring and summer seasons. This feature is mainly associated with the impact of NAO on winter precipitation, together with the strong dependence of spring and summer NDVI on contemporary water availability. NE shows a different behaviour, with positive (negative) values of winter NAO inducing high (low) values of NDVI in spring, but low (high) values of NDVI in summer. This behaviour mainly results from the strong impact of NAO on winter temperature associated with the critical dependence of vegetation growth on the combined effect of warm conditions and water availability during the winter season. (D'Odorico et al., 2002).

In both spring and summer NHCP over the Iberian Peninsula there is less precipitation variability under $\mathrm{NAO}^{+}$than under $\mathrm{NAO}^{-}$, especially in spring. This feature may be associated with the strong impact of climate variability in semi-arid areas, namely regarding effects of drought conditions on vegetation activity (Vicente-Serrano and Heredia-Laclaustra, 2004), in particular during the intense spring vegetation growth period. A weak dependence of vegetation greenness on temperature is also visible in spring, with median values of spring NVDI tending to decrease from $\mathrm{NAO}^{-}$to $\mathrm{NAO}^{+}$conditions. In the case of NHCP over NE there is a marked dependence of vegetation greenness on winter temperature, but the nature of such dependence is reversed from spring to summer. In spring there is a strong increase of NDVI from $\mathrm{NAO}^{-}$to $\mathrm{NAO}^{+}$, whereas a sharp decrease is observed for summer. Again the lower variability of temperature in the set of NHCP for $\mathrm{NAO}^{+}$, when compared with the corresponding one for $\mathrm{NAO}^{-}$, is evident.

Finally, the NAO impact on vegetation dynamics over the two regions was evaluated by studying the corresponding annual cycles of NDVI and comparing their behaviour for years associated with opposite NAO phases. In Iberia, the NAO impact is greater on non-forest 
vegetation, which responds rapidly to spatio-temporal variations in precipitation and soil moisture. During the summer, forests and other dense vegetation areas display the highest sensitivity to NAO dynamics. This vegetation shows slower response to precipitation, and the NAO impacts are delayed until late in the year. Over NE, the NAO impact is especially apparent during the first months of the year, suggesting that green vegetation growth tends to occur early and intensely in $\mathrm{NAO}^{+}$years due to the relatively warmer conditions associated to the absence of ice cover and early melting. NAO has a strong effect on temperature which, in turn, impacts vegetation activity. The latter impact is well depicted when comparing monthly values of NDVI for the first months of the year, under $\mathrm{NAO}^{+}$and $\mathrm{NAO}^{-}$(Figure 10).

The magnitude of the NAO-precipitation relationship in Iberia has been well documented in the literature over the last decade (e.g. Rodó et al., 1997; Trigo et al., 2002, 2004). However, only recently have such connections started to be taken into account when developing precipitation forecast models and predicting precipitation over the Iberian Peninsula with several months in advance (e.g. Gámiz-Fortis et al., 2002; Rodríguez-Fonseca and Castro, 2002). It is highly desirable that such models are implemented at the operational level because of their capacity of providing important seasonal forecasting information to be used by water resources and agricultural managers. However, it should be stressed that our lagged relationships between winter NAO and NDVI values for spring and summer already represent an added value since they allow formulating, by the end of March, simple outlooks of vegetation greenness for certain land cover types over the European region that may provide useful information in a wide range of application encompassing; crop forecasts, long-lead wildfire risk assessment and early warning for public health issues, such as polleninduced allergies.

\section{Acknowledgements}

This work was supported by the Portuguese Science Foundation (FCT) and European Space Agency (ESA) through project CARBERIAN (Terrestrial Vegetation Carbon Trends in the Iberian Peninsula) PDCTE/CTA/ 49985/2003. The large-scale gridded precipitation data set was kindly supplied by the Global Precipitation Climatology Centre (GPCC). The Satellite data was provided by the Global Inventory Monitoring and Modelling System (GIMMS) and the landcover thematic map was extracted from the Global Landcover Project (GLC2000).

\section{References}

Asrar G, Fuchs M, Kanemasu ET, Hatfeld JL. 1984. Estimating absorbed photosynthetic radiation and leaf area index from spectral reflectance in wheat. Agronomy Journal 76: 300-306.

Barnston AG, Livezey RE. 1987. Classification, seasonality and persistence of low-frequency atmospheric circulation patterns. Monthly Weather Review 115: 1083-1126.

Blenckner T, Hillebrand H. 2002. North Atlantic Oscillation signatures in ecosystems - a meta-analysis. Global Change Biology 8: $203-212$.
Bogaert J, Zhou L, Tucker CJ, Myneni RB, Ceulemans R. 2002 Evidence for a persistent and extensive greening trend in Eurasia inferred from satellite vegetation index data. Journal of Geophysical Research 107: 4119, DOI: 10.1029/2001JD00107.

Brown ME, Pinzon JE, Didan K, Morisette JT, Tucker CJ. 2006. Evaluation of the consistency of long-term NDVI time series derived from AVHRR, SPOT-Vegetation, SeaWIFS, MODIS and LandSAT ETM+. IEEE Transactions Geoscience and Remote Sensing 44: 1787-1793, DOI 10.1109/TGRS.2005.860205.

Buermann W, Anderson B, Tucker CJ, Dickinson RE, Lucht W, Potter CS, Myneni RB. 2003. Interannual covariability in Northern Hemisphere air temperatures and greenness associated with $\mathrm{El}$ Niño-southern oscillation and the Arctic Oscillation. Journal of Geophysical Research 108: 4396, DOI:10.1029/2002JD002.

Castro-Díez Y, Pozo-Vázquez D, Rodrigo FS, Esteban-Parra MJ. 2002. NAO and winter temperature variability in southern Europe. Geophysical Research Letters 29: 1160, DOI:.10.1029/2001GL014042. Cook BI, Mann ME, D'Odorico P, Smith TM. 2004. Statistical simulation of the influence of the NAO on European winter surface temperatures: Applications to phenological modeling. Journal of Geophysical Research 109: D16106, DOI:10.1029/2003JD004305.

D'Odorico P, Yoo JC, Jaeger S. 2002. Changing seasons: an effect of the North Atlantic Oscillation? Journal of Climate 15: 435-445.

Di L, Rundquist DC, Han L. 1994. Modeling relationships between NDVI and precipitation during vegetation growth cycles. International Journal of Remote Sensing 15: 2121-2136.

Gámiz-Fortis SD, Pozo-Vázquez D, Rodrigo FS, Esteban-Parra MJ, Castro-Díez Y. 2002. Spectral characteristics and predictability of the NAO assessed through Singular Analysis. Journal of Geophysical Research 107: 4685, DOI: 10.1029/2001JD001436.

Gouveia C, Trigo RM. 2008. In Influence of Climate Variability on Wheat Production in Portugal, geoENV VI-Geostatistics for Environmental Applications, Series: Quantitative Geology and Geostatistics, Vol. 15, Soares A, Pereira MJ, Dimitrakopoulos R (eds); 506, ISBN: 978-1-4020-6447-0 Springer-Verlag: Berlin Heidelberg, New York (in press).

Groisman PY, Karl TR, Knight RW. 1994. Observed impact of snow cover on the heat balance and the rise of continental spring temperatures. Science 263: 198-200.

Hansen J, Ruedy R, Glascoe J, Sato M. 1999. GISS analysis of surface temperature change. Journal of Geophysical Research 104: 30997-31022

Hurrell JW. 1995. Decadal trends in the north Atlantic oscillation: regional temperatures and precipitation. Science 269: 676-679.

Ji L, Peters AJ. 2003. Assessing vegetation response to drought in the northern Great Plains using vegetation and drought indices. Remote Sensing of Environment 87: 85-98.

Jones PD, Jonsson T, Wheeler D. 1997. Extension to the North Atlantic Oscillation using instrumental pressure observations from Gibraltar and south-west Iceland. International Journal of Climatology 17: 1433-1450.

Julien Y, Sobrino JA, Verhoef W. 2006. Changes in land surface temperatures and NDVI values over Europe between 1982 and 1999. Remote Sensing of Environment 103: 43-55.

Kaufmann RK, Zhou L, Knyazikhin Y, Shabanov N, Myneni RB, Tucker CJ. 2000. Effect of orbital drift and sensor changes on the time series of AVHRR vegetation index data. IEEE Transactions Geoscience and Remote Sensing 38: 2584-2597.

Kaufmann RK, Zhou L, Tucker CJ, Slayback D, Shabanov NV, Myneni RB. 2002. Reply to Comment on 'Variations in northern vegetation activity inferred from satellite data of vegetation index during 1981-1999 by J.R. Ahlbeck. Journal of Geophysical Research 107: 4127 10.1029/2001JD001516.

Keeling CD, Chin JFS, Whorf TP. 1996. Increased activity of northern vegetation inferred from atmospheric $\mathrm{CO} 2$ measurements. Nature 382: $146-149$

Los SO. 1998. Estimation of the ratio of sensor degradation between NOAA-AVHRR channels 1 and 2 from monthly NDVI composites. IEEE Transactions on Geoscience and Remote Sensing 36: 206-213.

Lotsch A, Tian Y, Friedl MA, Myneni RB. 2003. Land cover mapping in support of LAI/FPAR retrievals from EOS-MODIS and MISR: classification methods and sensitivities to errors. International Journal of Remote Sensing 24: 1997-2016.

Menzel A. 2003. Plant phenological anomalies in Germany and their relation to air temperature and NAO. Climatic Change 57: 243-263.

Myneni RB, Hall FG, Sellers PJ, Marshak AL. 1995. The interpretation of spectral vegetation indexes. IEEE Transactions on Geoscience and Remote Sensing 33: 481-496. 
Myneni RB, Keeling CD, Tucker CJ, Asrar G, Nemani RR. 1997. Increase plant growth in the northern high latitudes from 1981-1991. Nature 386: 698-702.

Pozo-Vázquez D, Esteban-Parra MJ, Rodrigo FS, Castro-Díez Y. 2001. A study of NAO variability and its possible non-linear influences on European surface temperature. Climate Dynamics 17: $701-715$

Qian B, Corte-Real J, Xu H. 2000. Is the North Atlantic oscillation the most important atmospheric pattern for precipitation in Europe? Journal of Geophysical Research 105: 901-910.

Rodó X, Baert E, Comin FA. 1997. Variations in seasonal rainfall in Southern Europe during the present century: relationships with the North Atlantic Oscillation and the El Niño-Southern Oscillation. Climate Dynamics 13: 275-284.

Rodríguez-Fonseca B, Castro M. 2002. On the connection between winter anomalous precipitation in the Iberian Peninsula and North West Africa and the Summer subtropical Atlantic sea surface temperature. Geophysical Research Letters 29: 1863, DOI: 1029/2001GL014421.

Rodriguez-Puebla C, Encinas AH, Nieto S, Garmendia J. 1998. Spatial and temporal patterns of annual precipitation variability over the Iberian Peninsula. International Journal of Climatology 18: 299-316.

Rogers JC. 1984. The association between the North Atlantic Oscillation and the Southern Oscillation in the Northern Hemisphere. Monthly Weather Review 112: 1999-2015.

Rudolf B, Schneider U. 2005. Calculation of gridded precipitation data for the global land-surface using in-situ gauge observations. Proceedings of the 2nd Workshop of the International Precipitation Working Group IPWG, Monterey, October 2004, EUMETSAT, ISBN 92-9110-070-6, ISSN 1727-432X, 231-247.

Saénz J, Rodriguez-Puebla C, Fernández J, Zubillaga J. 2001. Interpretation of interannual winter temperature variations over southwestern Europe. Journal of Geophysical Research 106: 20 641-20 651.

Serreze MC, Carse F, Barry RG, Rogers JC. 1997. Icelandic Low cyclone activity: climatological features, linkages with the NAO, and relationships with recent changes in the Northern Hemisphere circulation. Journal of Climate 10: 453-464.

Shabanov NV, Zhou L, Knyazikhin Y, Myneni RB. 2002. Analysis of Interannual Changes in Northern Vegetation Activity Observed in AVHRR Data during 1981 to 1994. IEEE Transactions on Geoscience and Remote Sensing 40: 115-130.
Stöckli R, Vidale PL. 2004. European plant phenology and climate as seen in a 20-year AVHRR land-surface parameter dataset. International Journal of Remote Sensing 25: 3303-3330.

Tanré D, Holben BN, Kaufman YJ. 1992. Atmospheric Correction Algorithms for NOAA-AVHRR products: theory and application. IEEE Transactions on Geoscience and Remote Sensing 30: 231-248.

Trigo IF. 2006. Climatology and Interannual Variability of StormTracks in the Euro-Atlantic sector: a comparison between ERA-40 and NCEP/NCAR Reanalyses. Climate Dynamics 26: 127-143.

Trigo RM, Osborn TJ, Corte-Real JM. 2002. The North Atlantic Oscillation influence on Europe: climate impacts and associated physical mechanisms. Climate Research 20: 9-17.

Trigo RM, Pozo-Vazquez D, Osborn TJ, Castro-Diez Y, GámisFortis S, Esteban-Parra MJ. 2004. North Atlantic Oscillation influence on precipitation, river flow and water resources in the Iberian Peninsula. International Journal of Climatology 24: 925-944.

van Loon H, Rogers JC. 1978. The seesaw in winter temperatures between Greenland and Northern Europe. Part I: general description. Monthly Weather Review 106: 296-310.

Vicente-Serrano SM, Heredia-Laclaustra A. 2004. NAO influence on NDVI trends in the Iberian Peninsula (1982-2000). International Journal of Remote Sensing 25: 2871-2879.

Vinnikov KY, Robock A, Stouffer RJ, Walsh JE, Parkinson CL, Cavalieri DJ, Mitchell JFB, Garrett D, Zakharov VF. 1999. Global warming and Northern Hemisphere sea ice extent. Science 286: 1934-1937.

Walker GT. 1924. Correlations in seasonal variations of weather. IX Memoirs of the Indian Meteorological Department 24: 275-332.

Wang GL, You LZ. 2004. Delayed impact of the North Atlantic Oscillation on Biosphere Productivity in Asia. Geophysical Research Letters 31: L12210, DOI: 10.1029/2004GL019766.

Wang J, Rich PM, Price KP. 2003. Temporal responses of NDVI to precipitation and temperature in the central Great Plains, USA. International Journal of Remote Sensing 24: 2345-2364.

Zhou L, Tucker CJ, Kaufmann RK, Slayback D, Shabanov NV, Myneni RB. 2001. Variations in northern vegetation activity inferred from satellite data of vegetation index during 1981 to 1999. Journal of Geophysical Research 106: 20069-20083. 